\title{
A Comparative Study on Experiential Teaching and Lecturing Teaching in the Course of College Students' Mental Health Education
}

\author{
Tian-lin Chen \\ Psychological Counseling Center \\ Jiangxi University of Traditional Chinese Medicine \\ Nanchang, Jiangxi, China \\ Lan Luo \\ School of Humanities \\ Jiangxi University of Traditional Chinese Medicine \\ Nanchang, Jiangxi, China
}

\author{
Zhen $\mathrm{Li}$ \\ Graduate School \\ Jiangxi University of Traditional Chinese Medicine \\ Nanchang, Jiangxi, China \\ Xiao-fei Xiao* \\ Higher Education Research Office \\ Jiangxi University of Traditional Chinese Medicine \\ Nanchang, Jiangxi, China \\ 289241871@qq.com
}

\begin{abstract}
In this paper, "SCL-90 Symptom Checklist" and the self-compiled "questionnaire on the satisfaction of teaching effect " were chosen, and 159 students from two classes $(78$ in the experimental group and 81 in the control group) are selected to explore the effect of experiential teaching and lecturing teaching in the course of college students' mental health education. What the experimental group received is experiential teaching and the control group is traditional teaching. The results of investigation show: 1. In pretest, the experimental group scored $121.84 \pm 7.23$ in SCL-90, and the control group scored $122.13 \pm 6.71$, there was no significant difference between the two groups $(t=-1.46, p<0.01) .2$. In posttest, the score of experimental group in SCL-90 was 91.87 \pm 8.56 , and that of control group was 121.25 \pm 9.32 , the difference between the two groups was very significant $(t=-8.31$, p<0.01). 3. $95.9 \%$ of students from the experimental group were satisfied with the experiential teaching, while only $42.9 \%$ of the students from the control group were satisfied with the traditional teaching, of which the gap was very large. Thus it can be achieved that in the course of college students' mental health education, the experiential teaching is more effective than lecturing teaching.
\end{abstract}

Keywords-Mental health education curriculum of college students; Experiential teaching; Lecturing teaching; Effect; Comparison

\section{INTRODUCTION}

At present, there are many problems in the course of college students' mental health education, it tends to be more academic and theoretical. Most of the classroom teaching is basically in the form of lecturing teaching, which impart knowledge rather than enable students to master practical psychological adjustment skills. This teaching style is teachercentered rather than student-centered. Students' interaction, experience, and participation in the classroom are few. As a result, students are more likely to stay in the shallower stage of perceptual awareness. It is hard to make people satisfied with the teaching effect [1]. The course of college students' mental health education is the main place to publicize mental health knowledge in colleges and universities. It is a difficult problem in the course of college students' mental health education that how to improve the teaching effect of college students' psychological health education, cultivate their good mental quality and improve their ability to cope with the psychological crisis.

The so-called experiential teaching is to enable students to understand and master the knowledge or skills they want to learn through their own practice, or to inspire students' emotions by evoking their past memories to implement the teaching [2]. Faced with various problems caused by lecturing teaching, the experiential teaching may provide an effective path for the realization of teaching objectives of mental health education.

\section{RESEARCH DESIGN}

\section{A. Objects and Methods of the Research}

1) Research Object

Class 2017, insurance class 1 of Jiangxi University of traditional Chinese medicine was selected as the experimental group, and Class 2017, insurance class 2 as the control group to implement the traditional teaching. There are 78 subjects in the experimental group and 81 in the control group. The ratio of men and women in the experimental group and the control group is basically similar. 


\section{2) Research Tools}

"SCL-90 symptom checklist" compiled by Derogatis L.R was used as a research tool. The scale consists of 90 items. From the perspectives of feelings, emotions, thinking, consciousness, behaviors, lifestyle habits, interpersonal relationships, diet and sleep, etc., it is assessed whether a person has certain psychological symptoms and how serious they are. Each item takes 1 to 5 grades, representing "no, very light, moderate, heavy, and serious". The scale is widely used at home and abroad with good reliability and validity. At the same time, the self-compiled "questionnaire on the satisfaction of teaching effect" is mainly used to understand students' satisfaction with teaching effectiveness.

\section{3) Research Procedures}

For the comparison of experiential teaching effect and lecturing teaching effect, two comparative variables are drawn up in this study. One is the influence of teaching methods on the mental health of students, and the second is the students' satisfaction with the teaching methods. "SCL-90 symptom checklist" was used to evaluate the mental health level of the experimental group and the control group (in pretest). Then, three teaching topics were selected as "interpersonal communication, emotional management, frustration and coping", and each topic was taught for 3 hours. The experimental group carried out experiential teaching while the control group carried out traditional lecturing teaching. After the topical teaching, the two groups of students were evaluated (in post-test) by using the "SCL-90 symptom checklist" and the "questionnaire on the satisfaction of teaching effect ". The data obtained was processed and analyzed with SPSS19.0.

\section{4) The experiential teaching method adopted}

Communication type. Teachers ask students observe a certain thing independently, using contrast and imagination to promote the communication between the students' emotions and thoughts, and then the teachers and students have the resonance of emotion and thought.

Discussion type. According to the content of mental education, teachers should design pertinent problems before teaching, and organize students to carry out simulation on the basis of problems, and then find solutions to the problems.

Activity type. It is a model that is most loved and welcomed by students. Teachers organize students to carry out various group activities, combine practical experience with theoretical knowledge, and encourage students to apply the knowledge they have learned into practice. Students can achieve teaching goals while discussing and interacting with each other.

Role simulation. The teachers create the real situation for the students according to the teaching content, and the students have opportunities to practice in a role-play simulation, and let the students find a solution to the problem through their efforts, and then accumulate the life experience.

\section{RESEARCH RESULTS}

A. Comparison between the experimental group and the control group in pretest

Table I shows that before implementing experiential teaching, the experimental group scored 121.84 \pm 7.23 in SCL90 , and the control group scored 122.13 \pm 6.71 . The difference between the two groups was not statistically significant.

TABLE I. SCL-90 SCORES COMPARISON BETWEEN THE EXPERIMENTAL GROUP AND THE CONTROL GROUP IN PRE-TEST

\begin{tabular}{|c|c|c|c|}
\hline & Experimental group & Control group & $\mathbf{t}$ \\
\hline Total score & $121.84 \pm 7.23$ & $122.13 \pm 6.71$ & -1.46 \\
\hline
\end{tabular}

\section{B. Comparison between the experimental group and the} control group in post-test

Table II shows that after implementing experiential teaching, the experimental group scored $91.87 \pm 8.56$ in SCL90 , and the control group scored 121.25 \pm 9.32 . The difference between the two is very significant.

TABLE II. SCL-90 SCORES COMPARISON BETWEEN THE EXPERIMENTAL GROUP AND THE CONTROL GROUP IN POST-TEST

\begin{tabular}{|c|c|c|c|}
\hline & Experimental group & Control group & t \\
\hline Total score & $91.87 \pm 8.56$ & $121.25 \pm 9.32$ & $-8.31^{* *}$ \\
\hline
\end{tabular}

C. Comparison between the experimental group in pretest and post-test

Table III shows that the experimental group scored significantly different in SCL-90 between before pre-test and post-test of experiential teaching.

TABLE III. SCL-90 SCORES COMPARISON BETWEEN PRE-TEST AND POSTTEST OF THE EXPERIMENTAL GROUP

\begin{tabular}{|c|c|c|c|}
\hline & Pre-test & Post-test & t \\
\hline Total score & $121.84 \pm 7.23$ & $91.87 \pm 8.56$ & $8.36^{* *}$ \\
\hline
\end{tabular}

D. Evaluation Comparison of Teaching Satisfaction between experimental and control Groups

Table IV shows that the satisfaction of experiential teaching among students in the experimental group is as high as $95.9 \%$; while the satisfaction of traditional teaching among students in the control group is only $42.9 \%$, and the gap is very large.

TABLE IV. ASSESSMENT COMPARISON OF TEACHING SATISFACTION BETWEEN EXPERIMENTAL AND CONTROL GROUPS $(\%)$

\begin{tabular}{|c|c|c|c|c|c|}
\hline Group & excellent & better & good & normal & worse \\
\hline Experimental group & 41.3 & 34.4 & 20.2 & 3.6 & 0.5 \\
\hline Control group & 5.9 & 12.3 & 24.7 & 50.8 & 6.3 \\
\hline
\end{tabular}




\section{ANALYSIS AND DISCUSSION}

The results of the study showed that the difference between the two groups in pretest was not significant on the score of SCL-90, but the score of the experimental group was significantly lower than that of the control group in post-test. The score of the experimental group was significantly lower in post test than that in pretest. The students' evaluation of the teaching satisfaction was far higher than that of the control group. This is consistent with the previous research results [3]. This shows that the effect of experiential teaching and traditional teaching on the promotion of mental health is different, and experiential teaching is relatively more effective. This is because in contrast to the traditional teaching, in experiential teaching teachers will actively create scenarios to guide students to experience educational scenarios actively, autonomously, and creatively and learn to avoid, overcome, and transform negative emotions and misunderstandings, and learn to develop, enjoy and use positive emotions and correct understanding, in which students can fully feel the joy in teaching activities, so as to achieve the purpose of promoting student self-development.

This kind of experiential teaching mode can promote students to explore actively and meet the characteristics of students' psychological development. It integrates psychological knowledge, mental health activity, and curriculum environment organically. Through teaching, students can get a full experience and profound understanding, so that they can acquire mental health knowledge imperceptibly. In other words, experiential teaching emphasizes students-centered in the teaching process, pays attention to the subjective initiative of the cognitive subject and the cultivation of self-learning ability, fully arousing the enthusiasm and passion of students' learning, improving the students' ability of hands-on, thinking, analyzing and innovating, and integrating the cognitive process with the emotional process. Students can learn the relevant knowledge content, realize the truth of life, choose behaviors patterns, and achieve self-education in experiential teaching [4].

\section{SUMMARY}

This study finds that experiential teaching is more effective than traditional lecturing in the course of College Students' Mental Health Education. However, due to the small sample size, the validity of the research results is limited. In the future, we can increase the sample size for further study. Of course, from the perspective of this study, the application of experiential teaching model is both an opportunity and a challenge for teaching. From the view of students, it is easier for students to learn the knowledge of mental health through experiential teaching, but it is difficult for the students who are not good at expressing bad words and having a special introversion to accept. The learning effect of the experiential learning is closely related to the motivation intensity of the students' participation in the experience. From the perspective of teachers, the creation of the experience situation is related to the effect of the entire class; and the experiential teaching model puts forward higher requirements for the teacher's ability to control the field and summarize the induction.

\section{SUGGESTIONS}

So, how to improve the effectiveness of experiential teaching in the teaching of mental health education? suggestions are as follows.

\section{A. Have a clear instructional design scheme}

In the process of designing the teaching plan, teachers should fully integrate the practical teaching, teaching goals, and teaching ideas of mental health, with psychological knowledge as an important foundation,

Design the content of thematic teaching and the overall teaching according to the teaching objectives, and let the students grasp the difficulties and key points of the course fully. Students can understand what problems are the key issues, which problems can be solved by their own efforts, which problems need to be discussed with students or teachers, which should be reflected in the teaching plan.

\section{B. Attach importance to the design of teaching situation}

Teachers should design the teaching scenarios scientifically based on the theoretical knowledge and the degree of difficulty. Through teaching props and multimedia technology, it creates a true teaching environment for students, allowing students to grasp the difficulties and key problems through the teaching situation, and bringing students the real experience of the senses and vision. In the process of designing teaching situations, teachers should follow the principle of free choice and equality for all. They should communicate with each student sincerely. Teachers should display amiable, affable, and sincere teachings on the basis of respect and equality. In view of different situations, teachers should design situational activities effectively, using multiple forms, computer software, film, music, animation and pictures to carry out activity in order to highlight the theme of education and to realize the harmony and unity of teaching content and situational activity activities.

\section{Focus on sharing and experiencing}

According to a certain grouping principle, the teacher groups the students scientifically, and the members of each group through the joint efforts summarize, communicate, and analyze the current psychological problems that students are prone to, and eventually come up with group solutions, which will be presented in the form of performances. The programs are presented to teachers and classmates. Through sharing and experience, students can develop a sense of cooperation and communication to listen to all useful opinions and ensure that all students are rewarded.

\section{Emphasis on internalization of experience}

After students' sharing and summarizing, the teachers should summarize the content of the teaching, emphasize the importance of mental health education and the purpose of teaching again, and guide students to think. We must fully integrate the theoretical knowledge we have learned with real life and learn to draw inferences from others so that if similar problems arise in life, students can solve them independently. 


\section{ACKNOWLEDGMENT}

Project supported by the subject of Teaching Reform of

College in Jiangxi Province (NO. JXJG-2014-12-16)

Corresponding author: Xiao-fei XIAO.

\section{REFERENCES}

[1] Yong-juan CHU. Application of Experiential Teaching Mode in Japanese Teaching in Colleges and Universities [J]. Exploration of Education, 2012, (1): 29-31. (In Chinese)

[2] Yin-xing YAN. An Empirical Study on the Effectiveness of Experientia Teaching in College Psychological Education [J]. Education and Occupation, 2012, (14): 153-154. (In Chinese)

[3] Su-qiong LUO. Practice Research on Experiential Teaching of the course of college students' mental health education. [J]. Research of Curriculum Education, 2017 (52): 171- 172. (In Chinese)

[4] Chang-xiang JIANG, Li-ting MAO. Practice Exploration of Experiential Teaching in University Mental Health Education Course [J]. Academic Journal of Education, 2013 (12): 76- 81. (In Chinese)

[5] Xu-yuan GU, Yan-ping WANG. A New Attempt of Experiential Teaching [J]. Journal of Shanghai Normal University, 2013 (3): 112-115. (In Chinese) 